\title{
Appropriate Term/Code Not Available Identified
}

National Cancer Institute

\section{Source}

National Cancer Institute. Appropriate Term/Code Not Available Identified. NCI

Thesaurus. Code C139466.

Problems is not adequately described by any other term. 